\title{
A trajetória de uma noção polêmica: análise crítica do populismo na teoria política de Ernesto Laclau.
}

Felipe Rafael Linden

\begin{abstract}
Felipe Rafael Linden
Doutorando e Mestre em Estudos Políticos na École des Hautes em Sciences Sociales, Paris. Mestre em Filosofia Contemporânea na École Normale Superieure/École des Hautes Études en Sciences Sociales, Paris.

E-mail: lindenfelipe@gmail.com
\end{abstract}

\begin{abstract}
Resumo: $O$ vocábulo populismo é confuso por causa de sua polissemia - assim como o conceito de "povo" do qual deriva; não obstante, os embates teóricos e políticos em torno do populismo são fatores agravantes desta dificuldade: trata-se, pois, de uma noção polêmica. Nesse sentido, traçar uma genealogia do conceito através de contextos e temporalidades parece-nos útil para se repensar o populismo, que se tornou uma passagem obrigatória da reflexão política contemporânea mesmo sem um acordo a minima sobre a sua definição. Em seguida faremos uma análise crítica da teoria formal do populismo proposta pelo filósofo argentino Ernesto Laclau (1935-2014). Apesar dele renovar a compreensão sobre o tema, ressignificando um termo que se tornou essencialmente negativo, pretendemos demonstrar que o seu modelo comporta um suposto déficit ou limite normativo.
\end{abstract}

Palavras chave: Populismo. Povo. América Latina e Europa. Teoria política. Ernesto Laclau. Déficit normativo.

\begin{abstract}
The word populism can be confusing because of its polysemy - as well as the concept of "people" from which it derives; nevertheless, the theoretical and political disputes surrounding the definition of populism are aggravating factors of this difficulty: it is therefore a polemical notion. In this sense, tracing a genealogy of the concept through contexts and temporalities seems to us useful to rethink populism, which has become an obligatory passage of contemporary political reflection without a minimum agreement on its definition. We will then make a critical analysis of the formal theory of populism proposed by the Argentine philosopher Ernesto Laclau (1935-2014). Although it renews the understanding on the subject, resignifying a term that has become essentially negative, we intend to demonstrate that its model bears a supposed deficit or normative limit.
\end{abstract}

Keywords: Populism. People. Latin america and Europe. Political theory. Ernesto Laclau. Normative deficit. 
A TRAJETÓRIA DE UMA NOČ̃O POLËMICA: ANÁLISE CRÍTICA DO POPULISMO NA TEORIA CRÍTICA DE ERNESTO LACLAU

Felipe Rafael Linden

\section{Introdução}

Tornou-se banal afirmar que o populismo é uma noção difícil de definir, constrangimento este que se expressa sistematicamente na literatura científica. Clarificar conceito tão usado e ao mesmo tempo tão ambíguo é um verdadeiro desafio para o pesquisador que decide se aventurar sobre o tema. Segundo o Blackwell Dictionary of Sociology: "[p]opulism is [...] a problematic concept for both political science and political sociology since this notion has been used and is still used to describe a multiplicity of phenomena that have important differences" (BRITO, 2007). Face a esta constatação, duas opções são possíveis: descartá-lo do vocabulário científico ou insistir no seu emprego. Margaret Canovan, no livro clássico que escreveu sobre o populismo, expõe o porquê que, segundo ela, decidir pelo abandono do termo seria uma escolha equivocada:

If the notion of "populism" did not exist, no social scientist would deliberately invent it; the term is far too ambigus for that. [...] However, the term does exist: there it is, firmly ensconced in a number of languages, constantly used by scholars and journalists alike [...] We cannot get rid of it [...] (CANOVAN, 1981: p. 301).

Ainda que o conceito possa apresentar falhas epistêmicas para a compreensão da realidade política que pretende cobrir, os fenômenos heterogêneos que são assim denominados comportam algo de específico que impede a sua classificação sob outros termos menos confusos, cuja definição seria de maior consenso. Nesse sentido podemos afirmar com Norberto Bobbio que o populismo é mais latente do que teoricamente explícito (BOBBIO, 1998: p. 980-986). É curioso notar que o tema ressurge periodicamente em diversas épocas e contextos nacionais e se impõe como passagem obrigatória de reflexão frente aos desafios da atualidade política. $O$ seu reaparecimento contemporâneo acontece nos anos noventa, onde partidos e movimentos políticos emergiram e ganharam notório capital político, alcançando países europeus até antes estranhos a manifestações populistas de tamanha amplitude.

\section{Do populismo latino-americano a "onda populista" na Europa}

Ao longo da primeira metade do século XX o populismo teve um papel de primeira ordem na América Latina. O cientista político Guy Hermet afirma que, se a Europa e a América do Norte foram o berço de nascença do populismo, a América Latina tornou-se posteriormente sua terra de eleição (HERMET, 2001: p. 205). Longe de ser um fenômeno marginal nesse continente, líderes populistas estiveram no centro do cenário político de diversos países, consolidando regimes e governos. Os seus arquétipos seriam Juan Domingo Péron (1895-1974) na Argentina e Getúlio Vargas (1883-1954) no Brasil, segundo Margaret Canovan (CANOVAN, 1981). Essas duas lideranças de importância maior - ainda que ambíguas - da história latino-americana seriam classificáveis como populistas em função do carisma e do apelo às massas à margem do sistema político vigente.

Nesse sentido, Hermet postula que o populismo na América Latina deve ser interpretado à parte, como um fenômeno que buscava responder às reivindicações democráticas de parcelas da população desprovidas de voz política. Apesar da importância dos líderes e regimes ditos populistas na história do continente, o termo empregado para os classificar carecia de clareza e consistência teórica. Fora então nos anos sessenta que essa lacuna deu lugar a tentativas de análise do populismo e que coincidem com o nascimento de uma ciência política de origem latino-americana. Os sociólogos ítalo-argentinos Gino Germani e Torcuato Di Tella, além do brasileiro Hélio Jaguaribe seriam os protagonistas da reflexão sobre essas experiências políticas dos anos trinta e cinquenta. Assim, o sociólogo francês Alexandre Dorna nota com justeza que "os sociólogos latino-americanos são praticamente os únicos a terem feito um exame exaustivo do populismo. Mas eles mesmos 
A TRAJETÓRIA DE UMA NOÇÃO POLËMICA: ANÁLISE CRÍTICA DO POPULISMO NA TEORIA CRÍTICA DE ERNESTO LACLAU

Felipe Rafael Linden

reconhecem a ambiguidade que torna o fenômeno quase elusivo" (DORNA, 1999: p. 106).

Entre esse corpus de trabalho que se inicia na década de sessenta, Germani foi um dos pioneiros a forjar uma definição científica do populismo (GERMANI, 1962, 1976). Observando o movimento peronista, o sociólogo teorizou o fenômeno sob o nome de "nacional-populista" - termo que foi importado e reconceitualizado na França pelo cientista político Pierre-André Taguieff nos anos oitenta. Os trabalhos de Germani $(1962 ; 1976)$ e ulteriormente de Di Tella (1965) fundaram uma perspectiva do populismo como forma política própria aos países sub-desenvolvidos. A transição de sociedades tradicionais em processo de industrialização rápida geraria uma "massa disponível" e desestruturada à mercê de líderes autoritários.

Apesar dos esforços de Germani e Di Tella, a perspectiva teleológica de um desenvolvimentismo modernizante por etapas, típico da sociologia da época, mostrou seus limites na compreensão do populismo. $O$ ressurgimento contemporâneo dos fenômenos assim designados em sociedades democráticas e altamente desenvolvidas aponta para a falha dessa explicação funcionalista. As primeiras reflexões de Ernesto Laclau acerca do tema aparecem na sequência desses estudos sobre o populismo, onde ele busca propor uma outra formulação teórica desvinculada de limitações históricas e geográficas. As análises de Germani e Di Tella são comentadas e criticadas por Laclau em seu primeiro livro publicado, Politics and Ideology in Marxist Theory (1977). Pode-se dizer assim que Laclau, que colaborou com Germani - na época professor da Universidade de Buenos Aires -, integra a linhagem de pesquisadores latino-americanos que se inicia na década de 1960, ansiosos por uma teoria do populismo, que teria marcado a história política do continente nas décadas anteriores.

Laclau analisa historicamente o surgimento desses fenômenos que, segundo ele, se devem a uma crise da hegemonia da classe dominante para neutralizar o antagonismo dessas interpelações populares. Nos anos setenta ele esboça uma reformulação do conceito de populismo à luz da teoria da interpelação de Althusser e de sua leitura de Gramsci no último capítulo, Towards a Theory of Populism. O populismo se constituiria, segundo ele, pela transformação de elementos populares em uma opção sintética e antagônica à ideologia dominante (LACLAU, 1977: p. 172-173).

Isso explicaria porque na América Latina, especialmente, surgiram tantos movimentos populistas entre os anos 1930-1960: no caso da Argentina, antes da crise da década de 1930, a classe hegemônica no poder era a oligarquia latifundiária e o liberalismo era seu princípio ideológico. Desde meados do século XIX, essa configuração dentro do sistema político seria constituída, de acordo com Laclau, através de uma dualidade: a entrada do país no mercado mundial e a concentração do poder político nas mãos desta oligarquia em um estado altamente centralizado, onde os interesses dessa minoria predominavam. No entanto, o sistema tinha condições limitadas para integrar as demandas populares e o populismo se radicalizou como conseqüência da hegemonia em torno desses valores liberais: "[d]emocracy and liberalism were opposed to each other" (LACLAU, 1977: p. 178).

Diante da instabilidade política, da imprecisão ideológica e das divisões da esquerda na Argentina na época, Laclau aponta que o peronismo, a principal força popular do país entre a direita e a esquerda, escaparia das categorias do marxismo ortodoxo ou da assimilação às correntes ideológicas existentes. No entanto, o interesse de Laclau pelo tema vai além da referências às experiências que viveu na Argentina: sua compreensão do populismo evolui até o ponto em que ele se revelará portador de uma lógica intimamente ligada aos postulados de sua ontologia política, como nós veremos mais adiante.

A discussão sobre o tema se impôs novamente com força nos anos 1990, justamente em razão do surgimento de uma "onda populista" no continente europeu. Nessa década de triunfo da democracia liberal sobre as experiências totalitárias do século XX, o "povo" se tornou a referência central no discurso de mobilização de líderes, partidos ou movimentos políticos que assumem uma posição de contestação ao establishment político e que são assim designados como populistas. Tal 
A TRAJETÓRIA DE UMA NOÇÃO POLËMICA: ANÁLISE CRÍTICA DO POPULISMO NA TEORIA CRÍTICA DE ERNESTO LACLAU

Felipe Rafael Linden

ressurgimento foi acompanhado de novas tentativas de definição da noção em razão da sua atualidade, sendo uma delas a teoria desenvolvida e publicada por Laclau em meados dos anos 2005.

No entanto, é notável que dentre diversas análises o populismo passou a ser tratado como um fenômeno essencialmente negativo, associado à movimentos de extrema direita e, portanto, uma ameaça maior e iminente para a democracia. A ideia mesmo de "povo" democrático passará a ser visto com um certa suspeição na medida em que os populistas fazem um bom desempenho nas urnas.

\section{3. "Populologia": a construção polêmica da noção de populismo}

A construção do populismo como categoria política depois dos anos sessenta fundou um ramo a parte entre a ciência política e a sociologia, a que o sociólogo Federico Tarragoni nomeia "populologia" (TARRAGONI, 2012). Os primeiros "populólogos"i tentaram sintetizar o fenômeno em torno de uma definição positiva e lhe atribuir assim um tipo ideal além das variações fenomenológicas. Mas essas tentativas não obtiveram os resultados esperados e a "populologia" contemporânea" alterou sua estratégia analítica. A característica distintiva desta nova fase seria a reconversão normativa do populismo em uma ameaça para a democracia (TARRAGONI, 2012: p. 97).

Tarragoni aponta que a "populologia" é marcada pelo cruzamento de duas histórias paralelas: o julgamento do populismo como antítese da democracia e o julgamento das classes populares como ameaça. Diferentes análises do "populismo" veiculam, em suma, uma aversão política à participação popular na democracia. Este pressuposto revelaria o caráter demofóbico do tratamento científico do populismo: uma representação estigmatizante da mobilização das camadas populares nos processos políticos. Essa representação tornou-se uma constante na construção progressiva do conceito de "populismo", levando a considerá-lo como uma patologia democrática.

Podemos afirmar que o aspecto polêmico em torno do tema remonta ao ganho de capital político de partidos europeus antes considerados como sendo de extrema direita ou mesmo percebidos como fascistas e que passaram a ser classificados como populistas no fim dos anos 1980. Talvez o exemplo mais emblemático na literatura científica é o de Pierre-André Taguieff (TAGUIEFF, 2012). Em 1984, ele teorizou e popularizou o "nacional-populismo" a fim de caracterizar o estilo político demagógico do partido Frente Nacional em plena ascensão no país, sob a liderança de JeanMarie Le Pen (TAGUIEFF, 1984). Antes marginal no cenário político francês, o partido em questão passa a captar o voto de operários e das classes populares. A partir do trabalho de Taguieff, o termo "populista" se impõe e é utilizado frequentemente por analistas para designar partidos semelhantes a Frente Nacional que também cresciam no continente europeu. Assim, reduzir o conceito de populismo a expressão do nacionalismo étnico e da xenofobia equivale a legitimar o discurso daqueles que vêem o povo como desprovido de capacidade política democrática.

Como resultado, ao reconhecer na denúncia do populismo uma representação pejorativa do povo como ator político, alguns autores reagiram à qualificação. Segundo Jacques Rancière, "além das polêmicas sobre os imigrantes, o comunitarismo ou o islamismo, o principal para eles é amalgamar a própria idéia do povo democrático à imagem da multidão perigosa" (RANCIÈRE, 2013: p. 138). Na mesma linha, a socióloga Annie Collovald critica o uso da categoria de populismo aplicado à Frente Nacional. Segundo ela, isso alimentaria a imagem negativa do povo: "julgados virem agora das camadas populares, aqueles que votam na Frente Nacional são julgados e sujeitos ao ressentimento irracional inerentes às suas diferentes "lacunas" (renda, educação, emprego...) (COLLOVALD, 2004: p. 73). As críticas de Rancière e Collovald ressaltam a estigmatização presente na utilização do populismo como uma acusação política, que visaria a participação das classes populares na política. O ressurgimento do populismo, agora relegado à extrema direita, seria assim 
A TRAJETÓRIA DE UMA NOÇÃO POLËMICA: ANÁLISE CRÍTICA DO POPULISMO NA TEORIA CRÍTICA DE ERNESTO LACLAU

Felipe Rafael Linden

diretamente ligado ao caráter supostamente ignorante do povo, irracional pois movido pelas "paixões tristes".

Trata-se de uma constatação similar com aquela feita por Laclau, também crítico da "populologia". A novidade da sua perspectiva teórica é ter operado a conversão das características atribuídas negativamente ao populismo em características da ação política em geral. Ernesto Laclau postula que o contexto desses pressupostos que pesam sobre as analises do populismo seria oriundo da "Psicologia das Multidões" no final do século XIX, de Gustave Le Bon (LACLAU, 2008). A partir daí, uma dicotomia é estabelecida entre o normal e o patológico e certos fenômenos políticos aqueles que mobilizam as multidões "perigosas" - passaram a ser considerados como aberrantes e irracionais. Este seria então um fator explicativo da ininteligibilidade do populismo: a desqualificação das massas em um modelo de racionalidade política que as ciências sociais não souberam romper.

Laclau defende uma razão própria ao populismo em desacordo com o senso comum e com a "populologia" contemporânea - isto é, o populismo não seria um desvio periférico e patológico, mas sim um fenômeno que aponta para um fundamento maior da ação política, entendido como um processo de construção do povo (LACLAU, 2008). É formulado assim um novo modelo de compreensão dos fenômenos políticos, no qual o populismo teria uma importância crucial.

\section{Aspectos da ontologia política de Ernesto Laclau: hegemonia, discurso e conflito}

Laclau mobiliza uma série de categorias filosóficas decorrentes de sua própria teoria política para pensar o populismo, elaboradas originalmente em Hegemony and Socialist Strategy (1985). Escrito com a filósofa Chantal Mouffe, neste trabalho o conceito de hegemonia inspirada em Antonio Gramsci entra em cena como uma categoria central para a compreensão da política, formulada através dos instrumentos filosóficos do pensamento pós-estruturalista (também conhecido sob o epíteto vago de French theory).

A observação de que o marxismo ortodoxo era inoperante diante da diversidade dos movimentos sociais que eclodem nos anos sessenta (os chamados New Social Movements. feminismo, anti-racismo, etc) leva-os a uma nova teoria política para reformar o projeto socialista. Daí o termo "pós-marxista" que os qualifica: a tarefa do socialismo seria produzir uma hegemonia através da articulação dessas várias lutas sociais para repensar o essencialismo de classe, que seria aos olhos de Laclau e Mouffe a contradição interna central da teoria marxista. Assim, os chamados temas "culturais" ou "identitários" não deveriam ser subjugados à política "real", cuja perspectiva da luta de classes é percebida como único referente legítimo da mobilização política.

Através da aceitação de uma pluralidade de lutas irredutíveis ao pertencimento de classe, Gramsci teria estabelecido, segundo eles, "os fundamentos de uma prática democrática da política, compatível com uma pluralidade de sujeitos históricos" (LACLAU; MOUFFE, 2009: p. 147). No entanto, apesar dessa mudança radical que ele teria operado no campo teórico do marxismo, permanecem vestígios de essencialismo de classe que Laclau e Mouffe desejavam se livrar. Como resultado, eles generalizam a categoria de articulação para elaborar o conceito de hegemonia: para eles, não há identidade política externa ao campo onde a prática articulatória da hegemonia opera. Em outras palavras, a existência de sujeitos políticos ou da ordem estabelecida resulta da articulação entre vários grupos sociais.

As consequências do papel central da hegemonia são numerosas para a teoria política de Laclau e consequentemente também para a compreensão do populismo. Nós confiamos na análise de Olivier Marchant para sumarizar (MARCHANT, 2007: p. 17-18). Pode-se dizer que a primeira conseqüência é a afirmação da "autonomia" da política através da desconstrução da ortodoxia marxista da divisão da sociedade em classes; a política não pode mais ser vista como dependente de uma "realidade" ou lei social mais profunda - sob o modelo superestrutura/infraestrutura, o processo 
A TRAJETÓRIA DE UMA NOČ̃O POLËMICA: ANÁLISE CRÍTICA DO POPULISMO NA TEORIA CRÍTICA DE ERNESTO LACLAU

Felipe Rafael Linden

dialético etc. - mas, pelo contrário, é a política que instituiria o social. Assim, a segunda consequência é a possibilidade infinita de configurações de identidades políticas para além da lógica binária de classes - o proletariado como classe universal determinada pela relação econômica da produção perde seu privilégio ontológico e torna-se uma identidade política entre outras. A terceira consequência é a extensão da noção de hegemonia a uma teoria do discurso: o próprio social é pensado como um espaço discursivo habitado por diferenças discursivas, cada uma tentando "saturar" o significado da sociedade - a multiplicidade das identidades políticas é, portanto, o produto de construções discursivas diversas.

Marchant afirma que Hegemony emprega pela primeira vez a filosofia pós- estruturalista como ferramenta de análise política. A definição de espaço social como espaço discursivo significa que as relações políticas são contingentes, produzidas pelo significado. A noção de discurso de Laclau e Mouffe é em grande parte tributária da teoria de Michel Foucault - mais precisamente através da apropriação reformulada da noção de "formação discursiva" introduzida na obra Archéologie du savoir (1969). Entendido como regularidade na dispersão, significa que o discurso tenta unificar elementos heterogêneos em um todo coerente, sem que esses elementos tenham relação entre eles.

No entanto, Laclau e Mouffe rejeitam a distinção entre práticas discursivas e não discursivas que Foucault opera. Toda prática social seria determinada por uma produção social de significado, e qualquer objeto é, portanto, um objeto de discurso. "Não há nada fora do texto", como Jacques Derrida postulava, é retomado por Laclau e Mouffe: significa que nada escapa às redes simbólicas qualquer coisa "concreta" é inseparável do seu aspecto discursivo que preside a sua formação e existência social. Nas palavras de Laclau: "o discurso constitui o principal fundamento de constituição da objetividade enquanto tal" (LACLAU, 2008: p. 86).

A categoria de discurso é definida então como um "conjunto de elementos em que as relações desempenham um papel constitutivo" (LACLAU, 2008: p. 86). Essa perspectiva tributária do linguista Ferdinand de Saussure não pensa a linguagem constituída por termos positivos, mas sim pela relação entre seus elementos - e é a diferença entre os termos que permitem o seu significado, isto é, não existiriam significados externos às relações; em última instância, há apenas discursos. Um exemplo: discutir sobre o discurso de um partido não teria sentido para Laclau e Mouffe uma vez que o partido é um discurso entre outros que procuram representar o significado da realidade. Da mesma maneira, o populismo é um discurso que compete para estabelecer o significado do povo.

A partir deste jogo de diferenças discursivas que constituem o espaço social, podemos entender por que, para esses autores, a sociedade é um objeto impossível, uma vez que não pode ser constituída como uma totalidade, pois é sempre - e para sempre - incompleto. Em outras palavras, não há um horizonte possível para a reconciliação da sociedade sob um conteúdo específico - e é a própria impossibilidade da sociedade que torna a política possível e indispensável. O relato hegeliano do fim da história, do qual o comunismo foi tributário, mas também sua versão liberal fukuyamista, onde a política se tornaria obsoleta, é rejeitada. Desta forma, a política é percebida como uma questão de decisão tomada em um contexto de incerteza, uma prática sem uma regra que a justifique, sem princípio fundador ou regulador.

A sociedade é impossível, porém ela é necessária: se a determinação do significado da sociedade é impossível - sendo irreconciliável, não pode, portanto, constituir uma totalidade fechada - uma fixação parcial do significado deve ser operado através da hegemonia: "o social é articulação uma vez que a sociedade é impossível" (LACLAU; MOUFFE, 2009: p. 211). Caso contrário, viveríamos em um mundo psicótico sem significação possível. Isso constituiria o papel da política e sua dimensão performativa: fazer uma particularidade desempenhar temporariamente a representação de uma totalidade impossível a atingir plenamente.

E como essa operação seria possível? Laclau pensa que a particularidade deve ser transformada em "significado vazio": "[t]he relation by which a particular content becomes the 
A TRAJETÓRIA DE UMA NOČ̃O POLËMICA: ANÁLISE CRÍTICA DO POPULISMO NA TEORIA CRÍTICA DE ERNESTO LACLAU

Felipe Rafael Linden

signifier of the absent communitarian fullness is exactly what we call a hegemonic relationship. The presence of empty signifiers [...] is the very condition of hegemony" (LACLAU, 1996: p. 35). Em suma, trata-se de um significante que se divide em dois: não deixa de ser uma particularidade, mas assume a representação de uma totalidade e que se torna uma espécie de âncora simbólica para as outras particularidades dispersas no campo discursivo. $O$ significante vazio aparece assim como uma categoria central para pensar a hegemonia e o populismo (veremos que o "povo" é um significante vazio).

A própria democracia tem como condição sine qua non essa falta de fundamento, caracterizada pelo "lugar vazio do poder" como teorizado por Claude Lefort (1981) e que tem o conflito como motor. Segundo Laclau, "[i]f democracy is possible, it is because the universal has no necessary body and no necessary content; different groups, instead, compete between themselves to temporarily give to their particularisms a function of universal representation" (LACLAU, 1996: $p$. 35). Assim, a política pensada por Laclau e Mouffe é inspirada em Nietzsche pela impossibilidade de conciliar todos os pontos de vista. O conflito (o agôn nietzscheano) é, portanto, um aspecto insuperável nas relações sociais: o antagonismo decorre da impossibilidade da sociedade se constituir plenamente, isto em função da abertura e da indeterminação do espaço social. Assim, o conflito e a divisão social não seriam um problema político a ser resolvido, mas algo a ser desejado no regime democrático.

O conflito pressupõe o estabelecimento de fronteiras políticas e identidades coletivas derivadas deles. É através dessas premissas que a lógica populista ganha corpo, constituindo uma oposição do tipo "nós" e "eles" para construir politicamente a identidade popular.

\section{Construir o povo: do significante vazio a identidade popular}

Na obra On the populist reason (2008), o populismo se generaliza como uma lógica política. A idéia de "interpelação" apresentada em sua primeira definição em Politics and Ideology in Marxist Theory (1977) é substituída pela ideia de "construção" da identidade popular. Laclau aponta a formação de identidades coletivas, políticas e sociais, como uma questão central para formular sua tese sobre o populismo. Para ele, construir uma vontade coletiva é o processo político por excelência, através da reunião de diversas reivindicações que existirão socialmente em torno e através de um discurso. Essa característica fundamental da política é precisamente a razão populista, que mobiliza o povo como referente da identidade política.

O povo não seria a totalidade dos cidadãos de uma determinada comunidade política (o populus na terminologia latina) nem a base da pirâmide social (a plebs). 0 populismo mantém a tensão entre a própria ambiguidade das definições políticas do povo através de uma operação complexa, em que uma parte da sociedade composta por vários setores deseja representar suas reivindicações como as da sociedade como um todo. O povo seria, portanto, um "significante vazio", uma identidade a ser construída e reconstruída perpetuamente. E é aí que o populismo entra em jogo, como dispositivo discursivo no qual o povo emerge enquanto sujeito politico.

Para Laclau, há uma tensão entre a lógica da diferença e a lógica da equivalência própria ao populismo. Há demandas sociais que, satisfeitas pelo poder, permanecem isoladas em relação a outras demandas uma vez que são totalizadas pelo sistema institucional. Numa situação em que uma série de demandas endereçadas a este sistema institucional são frustradas, a equivalência entre essas diferentes reivindicações pode constituir uma subjetividade social mais ampla, constituindo uma luta política comum pela suspensão da diferença entre as demandas particulares que a compõem.

Isso constitui o elo inicial do populismo através do estabelecimento de uma fronteira antagônica: trata-se de uma mobilização política em torno de um discurso que dá forma a um "nós" contra "eles", e a identidade de cada um dos lados é correlata e pode ser atravessada por todo tipo 
A TRAJETÓRIA DE UMA NOČ̃O POLËMICA: ANÁLISE CRÍTICA DO POPULISMO NA TEORIA CRÍTICA DE ERNESTO LACLAU

Felipe Rafael Linden

de conteúdo político. Por isso o populismo é antes de tudo uma necessidade formal através da qual diferentes movimentos e ideologias podem tomar forma. Trata-se da necessidade de constituir uma identidade política para expressar a divisão social, estabelecendo dessa maneira uma fronteira antagônica contra a hegemonia do poder estabelecido. Como o sistema institucional não é capaz de integrar toda uma série de demandas populares contrárias às formas sedimentadas do social, - 0 que na linguagem da teoria do discurso seriam práticas discursivas sedimentadas pela hegemonia então o populismo surge pela negação das relações sociais existentes.

Diferentemente de um "estilo político" que se confunde com a demagogia, como afirma Taguieff, o populismo é finalmente concebido como um dispositivo neutro: Laclau postula que não existe uma unidade referencial interna ao conceito. Seria, portanto, uma forma política e não um conteúdo ideológico específico. Assim, o esforço para identificar um conteúdo político próprio ao populismo seria um exercício vão, uma vez que se trata de movimentos políticos cujas bases sociais são divergentes. O populismo representa antes de tudo uma função ontológica, uma possibilidade de estruturar a luta política através do estabelecimento de uma fronteira entre "nós" e "eles". Esta seria a principal falha de tentativas de definição do "populismo": "quanto mais o conceito geral incorpora definições precisas, menos ele é capaz de abranger análises concretas" (LACLAU, 2008: p. 22).

O populismo não é a expressão de um grupo já constituído e identificável na estrutura social, é de fato o oposto: trata-se de uma identidade popular retroativa. A cristalização da identidade popular envolve uma luta pela hegemonia para encontrar sua própria consistência quando a pluralidade de demandas é unificada em um sistema estável de significados que darão corpo ao povo. Assim, entender o povo sob os termos de um sujeito político construído em torno de um significante vazio nos leva a assumir a ambiguidade ideológica do populismo.

A luta para determinar o conteúdo ideológico que dá forma ao significante vazio, que também poderia ser descrito como a luta política eo ipso para Laclau, constitui o nível ôntico do populismo. No entanto, há uma primazia do papel ontológico sobre o conteúdo ôntico: o uso da lógica populista muitas vezes é mais importante do que os significantes ideológico-políticos que the dão substância. É através da lacuna entre estes dois níveis, ou seja, um conteúdo político que incorpora a necessidade ontológica de expressar a divisão social, que nos permite compreender como operam as variações de um populismo ao outro, ou como a identidade popular pode ser construída de maneiras opostas.

Verificamos assim o formalismo da análise de Laclau: seu modelo não permite definir um populismo "bom" ou "ruim". O populismo seria a expressão de uma necessidade formal de expressar a divisão social, de estabelecer um confronto antagônico à hegemonia do poder estabelecido através da construção de um povo.

\section{Populismo como lógica política neutra: limites normativos}

Laclau erige a construção do povo como a principal tarefa política democrática (LACLAU, 2016), e assim podemos considerar seu entendimento do populismo como uma teoria normativa. 0 populismo é assim libertado do impasse na definição do conceito: ele não deve ser identificado com uma certa posição no espectro ideológico e não representaria necessariamente um perigo para instituições democráticas como seria confortável acreditar, mantendo uma certa visão das classes populares como um problema político a ser neutralizado em nome do bom funcionamento das instituições.

No entanto, se seguirmos o rigor da análise de Laclau, a necessidade de uma identidade coletiva para expressar divisão social é mais forte do que o conteúdo que será veiculado a ela. 0 rigor de tal compreensão do populismo também pode revelar-se sua fraqueza, pois a nosso ver a dimensão ética do conflito, que a lógica política do populismo acentua, não é levada em consideração. Se o populismo não é bom nem ruim, ele é simplesmente a expressão da divisão 
A TRAJETÓRIA DE UMA NOČ̃̃ POLËMICA: ANÁLISE CRÍTICA DO POPULISMO NA TEORIA CRÍTICA DE ERNESTO LACLAU

Felipe Rafael Linden

social e do antagonismo (como características ontológicas da política), como avaliar a variedade de identidades populares que podem se construir em torno do conflito?

Esta é precisamente a crítica de Jan-Werner Muller dirigida a Laclau: "[a] política é sinônimo de conflito, mas o que ganhamos recorrendo a esses tipos de expressões [populistas] que, se não investem no nacionalismo identitário, não deixam de flertar com uma retórica chauvinista?" (MULLER, 2016: p. 168). Muller faz um paralelo com o lema do movimento Occupy Wall Street, o "We are the 99\%" e o discurso populista que afirma "Nós somos os $100 \% "$ ". O populismo seria, portanto, anti-pluralista. O fato de o discurso "populista" afirmar falar em nome da sociedade como um todo é potencialmente perigoso, segundo Muller, à esquerda ou à direita. A suposição errônea de uma totalidade social significa que existe, para os populistas, o povo real e outros membros da sociedade, que não fazem realmente parte dela e devem ser excluídos politicamente.

Se observarmos a atual realidade sócio-política, encontramos um equilíbrio de poder assimétrico tendente ao populismo de direita ou de extrema direita na maioria dos outros países europeus. No entanto, como vimos, a teoria de Laclau se recusa a dar critérios para julgar uma prática populista de outra. Inspirado por Gramsci, a única ética possível é a decisão "ético-política"; isto é, o investimento político dos atores em uma determinada situação seria o único momento ético concebível. A contingência radical desse modelo não permite uma regra exterior à ação política. A este respeito, Simon Critchley percebe um suposto déficit normativo na construção teórica de Laclau.

Critchley afirma que, sem uma dimensão ética, a lógica da hegemonia corre o risco de cair no arbitrário e no puro decisionismo (CRITCHLEY, 2008). Daí a possibilidade de um déficit normativo em sua teoria política. Esta crítica nos interessa porque a construção do povo, como já vimos antes, é uma operação hegemônica descrita por Laclau. Diante das críticas à neutralidade de sua teoria, Laclau nega a possibilidade de um puro decisionismo (a idéia de um sujeito onipotente) e tenta desconstruir a oposição entre o descritivo e o normativo. Segundo ele, é impossível fazer uma descrição neutra dos fatos. Sempre há elementos normativos que acompanham, sempre há um certo julgamento da realidade quando a descrevemos.

Logo depois, Laclau adiciona ao sistema uma distância entre a ética e o normativo. A ética, segundo ele, também seria um "significante vazio". Isto é, "a experiência ética tende a se expressar através de termos como 'verdade', 'justiça', 'dever' - ninguém negaria seu caráter ético, mas esses termos podem se referir a diferentes conteúdos normativos" (LACLAU, 2004). A relação entre ética e um conteúdo normativo particular pressupõe um contexto para Laclau e não seria possível ou desejável, portanto, estabelecer critérios normativos para julgar um tipo de movimento político. Ou seja, a ética é esvaziada de conteúdo porque não seria desejável julgar um evento político sem analisar o contexto em que ocorre, ou seja, ela se encarnaria apenas em uma situação política particular impossível de prever, pois depende do investimento de atores políticos nesses significantes vazios. Preferimos então dizer que existe um limite normativo na teoria de Laclau ao invés do déficit denunciado por Critchley, uma vez que interpretamos a análise do populismo como uma teoria normativa.

\section{Considerações finais}

O formalismo da teoria de Laclau, pouco receptivo à discussão de critérios éticos e normativos que ele considera "apolíticos", pode ser interpretado como uma vantagem ou desvantagem de seu modelo. Nós o interpretamos como ambos. É uma vantagem na medida que permite analisar as variações populistas como diferentes encarnações de uma forma neutra, refletindo, através da sua neutralidade, a falta de fundamento e a indeterminação própria à democracia. A sua desvantagem deriva da mesma razão: ficamos sem critérios normativos para julgar o populismo.

A questão seria: para evitar o riscos do arbitrário e do relativismo, de que maneira introduzir 
A TRAJETÓRIA DE UMA NOČ̃̃ POLËMICA: ANÁLISE CRÍTICA DO POPULISMO NA TEORIA CRÍTICA DE ERNESTO LACLAU

Felipe Rafael Linden

critérios para avaliar as diferentes maneiras pelas quais o povo é construído pelo discurso populista, - em torno da expressão da divisão social em um determinado contexto - sem asfixiar a contingência radical própria à política que Laclau defende? A este respeito, Laclau formulou uma explicação contextualista e Mouffe, à sua maneira, deu sugestões bastante amplas em resposta a esta questão, propondo um "consenso conflituoso" - no entanto, não diz como as divergências serão realmente resolvidas no seu modelo de pluralismo agonístico. Embora seja verdade que eles formularam uma outra maneira de pensar o político ao aceitar o conflito e a contingência, a partir da qual o populismo seria uma expressão positiva, do ponto de vista da filosofia a resposta que traz aos atores políticos é insatisfatória: a produção do conflito se baseia exatamente em razão da convicção de cada um em sua própria causa ou luta política, o que obscurece tendencialmente a contingência das lutas como um todo.

A análise de Laclau do populismo é governada por suas posições pós-estruturalistas, desenvolvidas com Mouffe, segundo as quais há apenas discursos em competição no mundo social, entendido ele mesmo como espaço discursivo - de modo que nada motive racionalmente a escolha entre tal e qual discurso. No final se impõe aquele que se torna hegemônico. Como vimos acima, as variações populistas podem ser explicadas como o efeito da contingência irredutível na construção do povo, este último sendo resultado de uma luta pela hegemonia que não pode ser antecipada.

A partir dessas posições anti-essencialistas, revela-se um certo relativismo que leva a uma perspectiva cínica da política: em última instância, há apenas conflito e antagonismo, o que constitui uma ontologia política polêmica. O risco de uma compreensão "pragmática" da política é a arbitrariedade e o puro decisionismo. Pode-se argumentar que o conflito e a divisão não só são insuperáveis mas desejáveis nas sociedades democráticas, que se caracterizam pelo fato do lugar de poder ser vazio, sem cair no que pode parecer uma concepção irrazoável da política.

(Recebido para publicação em dezembro de 2017)

(Reapresentado em abril de 2018)

(Aprovado para publicação em junho de 2018)

\section{Cite este artigo}

LINDEN, Felipe Rafael. A Trajetória de uma Noção Polêmica: Análise Crítica do Populismo na Teoria Crítica de Ernesto Laclau. Revista Estudos Políticos: a publicação semestral do Laboratório de Estudos Hum(e)anos (UFF). Rio de Janeiro, Vol 9 | N.1, pp. 20 -31, julho de 2018. Disponível em: http://revistaestudospoliticos.com/

\section{Notas}

1 Obras citadas: IONESCU, Ghita ; GELLNER, Ernest. Populism : Its Meaning and National Characteristics. Londres : Weidenfeld \& Nicholson, 1969 ; GERMANI, Gino. Política y Sociedad en una época de transición. Buenos Aires : Paidos, 1962 ; CANOVAN, Margaret. Populism. New York : Harcourt Brace Jovanovich, 1981. 2 PERRINEAU, Pascal (dir.). Les Croisés de la société 
A TRAJETÓRIA DE UMA NOÇÃO POLËMICA:
ANÁLISE CRÍTICA DO POPULISMO NA ANALISE CRITICA DO POPULISMO NA
TEORIA CRIITICA DE ERNESTO LACLAU

Felipe Rafael Linden

fermée : L'Europe des extrêmes droites. La Tour d'Aigues : L'aube, 2001 ; HERMET Guy, Les populismes dans le monde. Paris, Fayard/ L'espace du politique, 2001 ; REYNIE Dominique. Populismes : la pente fatale. Paris, Plon, 2011 ; TAGUIEFF, Pierre-André. Le nouveau national-populisme. Paris : Éditions CNRS, 2012.

\section{Bibliografia}

BOBBIO, Norberto; MATTEUCCI, Nicola; PASQUINO, Gianfranco. Dicionário de política. Brasília: Editora Universidade de Brasília, 1998.

BRITO, Myriam. "Populism". In: Blackwell Encyclopedia of Sociology. Ritzer, George (ed). Blackwell Publishing, 2007. Blackwell Reference Online. Disponível em:

$<$ https://www-sociologyencyclopediacom.sargasses.biblio.msh-paris.fr/subscriber/ tocnode.html?id=g9781405124331_yr2012_chunk_g9 78140512433122_ss1-66>.

CANOVAN, Margaret. Populism. New York: Harcourt Brace Jovanovich, 1981.

COLLOVALD, Annie. Le «populisme du FN»: un dangereux contresens. Paris: Éditions du Croquant, 2004.

CRITCHLEY, Simon. ¿Hay un déficit normativo en la teoría de la hegemonía? In: CRITCHLEY, Simon; MARCHANT, Olivier (ed.). Buenos Aires: Fondo de cultura económica, 2008, pp.145-156.

DI TELLA, Torcuato S. Populismo y Reforma en América Latina. Desarrollo Económico, 1965, no.16. DORNA, Alexandre. Le populisme. Paris: PUF, 1999. FOUCAULT, Michel. L'Archéologie du savoir. Paris: Gallimard, 1969.

LACLAU, Ernesto; MOUFFE, Chantal. Hégémonie et stratégie socialiste: vers une politique démocratique radicale. Paris: Les Solitaires Intempestifs, 2009.

LACLAU, Ernesto. Emancipation(s). London: Verso, 1996.

LACLAU, Ernesto. Ethics, Normativity and the Heteronomy of Law. In: Sinkwan Cheng (ed.). Law, Justice and Power: Between Reason and Will. Palo Alto: Stanford University Press, 2004. p. 177-186.

LACLAU, Ernesto. La raison populiste. Paris: Seuil, 2008.

LACLAU, Ernesto. Politics and Ideology in Marxist Theory: Capitalism, Fascism, Populism. Londres: NBL, 1977.

LACLAU, Ernesto. Why Constructing a People Is the Main Task of Radical Politics. Critical Inquiry, 2016, 
A TRAJETÓRIA DE UMA NOCÃO POLËMICA: ANÁLISE CRÍTICA DO POPULISMO NA TEORIA CRÍTICA DE ERNESTO LACLAU

Felipe Rafael Linden

no.4, pp. 646-680.

LEFORT, Claude. L'Invention démocratique, Paris, Fayard, 1981.

GERMANI, Gino. Authoritarianism, Fascism, and National Populism. New Brunswick: Transaction Books, 1978.

GERMANI, Gino. Política y Sociedad en una época de transición. Buenos Aires: Paidos, 1962.

HERMET, Guy. Les populismes dans le monde. Paris: Fayard, 2001.

MARCHANT, Olivier. Post-Foundational and political thought. Edinburgh: Edinburgh University Press, 2007. MULLER, Jan-Werner. Qu'est-ce que le populisme? Définir enfin la menace. Paris: Premier Parallèle, 2016. RANCIĖRE, Jacques. "L'introuvable populisme". In: BADIOU, Alain; BOURDIEU, Pierre; BUTLER, Judith et al. Qu'est-ce qu'un peuple? Paris: La fabrique des éditions, 2013. pp.138-142.

TAGUIEFF, Pierre-André. Le nouveau nationalpopulisme. Paris: Éditions CNRS, 2012.

TAGUIEFF, Pierre-André. "La rhétorique du nationalpopulisme. Les règles élémentaires de la propagande xénofobe". Mots, 1984, no.9, pp.113-139.

TARRAGONI, Federico. Thèse: «Il faut faire le peuple!», sociologie d'un populisme «par le bas» dans les conseils de barrio en Amérique Latine contemporaine (Venezuela et Bolivie). (Não publicado, tese defendida em 2012).ADORNO, Sergio; BORDINI, Eliana B. T; LIMA, Renato Sergio de. O adolescente e as mudanças na criminalidade urbana . São Paulo Perspec. [online]. 1999, vol.13, n.4, pp.62-74. 